\title{
Structure Features, Damage and Treatment of Two Pottery artifacts from Tel El-Shobak, Qalyubia, Egypt: Case Study
}

walid kamel elghareb ( $\square$ walidelghareb@yahoo.com )

Zagazig University, Sharkia

Research article

Keywords: Pottery, Additives, Damage, Treatment, poultice, Nano-Silica

Posted Date: September 20th, 2021

DOl: https://doi.org/10.21203/rs.3.rs-876585/v1

License: (1) (1) This work is licensed under a Creative Commons Attribution 4.0 International License.

Read Full License 


\section{Abstract}

The research paper aims to identify structure features, damage and treatment of two pottery artifacts from Tell Al-Shobak in Qalyubia, "one of the archaeological sites dating back to new kingdom". Polarized Microscopy "PLM", Scanning Electron Microscope with Energy dispersive X-ray unit "SEM-EDX", X-Ray Diffraction analysis "XRD", and Differential thermal analysis "DTA" were adopted for investigating and analyzing pottery sherds. The research identified structure features proving that the used clay is Nile clay, the additives are sand, grog and calcite. The formation technique is potter wheel The surface treatment is slip layer. The firing atmosphere is oxidizing. Firing temperature might be about $726.78^{\circ} \mathrm{C}$ The first pottery vessel and $737.80^{\circ} \mathrm{C}$ for the second pottery plate. Research also proved that pottery pieces suffer from various damage aspects such as soil deposits, stains, cracking, fracture, loss of some parts, lack of durability, weakness, and salt crystallization. The studied pottery pieces treated using mechanical cleaning method and chemical cleaning using a mixture of acetone and toluene at a ratio of 1:2 respectively to remove clay soil deposits. EDTA applied to remove lime deposits. Hydrogen peroxide20 \% was used to remove soot. Nano Silica $1 \%$ was applied to strengthen archaeological pottery .Assembling the pottery sherds was done by Paralloid B72 50\%. Replacement pottery sherds conducted by Microballoon and grog in a ratio of 2:1, respectively. After treatment, the pottery artifacts were ready for museum display.

\section{Introduction}

Tell al-Shobak is located near the city of Shebin el-Qanater, northeast of Banha; Qalyubia Governorate, Egypt [1].The governorate includes some archaeological sites such as Tell Atrib, Tell el-yahudiyah and Tell al-Shobak [2], which represents the eighth region of the Lower Egypt provinces [3]. Excavations have revealed many pottery artifacts [4].The excavated pottery pieces suffer from various damage manifestations such as soil sediments, cracking, crystallization of salts, various stains, fractures and loss of some parts [5] which requires examination, analysis, restoration and maintenance based on the results of examinations and analyzes. Restoration and treatment methods depend on damage condition of pottery pieces. Choosing appropriate cleaning method is not an easy and simple process due to multiplicity and diversity of used materials for restoration, treatment, and maintenance. This process has become one of the important topics in the field of treatment [6].Many different cleaning materials used depending on the damage. Among modern used materials in cleaning process recently are carbogel [7]. EDTA used to remove various lime deposits (Orabi and [8], organic solvents for removal soil sediments [9]. Hydrogen peroxide applied to clean soot [10], di chloro methane give the same result [11]. Nano-micro emulsions cleansers are liquid, stable and transparent $\mathrm{O} / \mathrm{W}$ micro emulsions [12]. Most of the pottery artifacts have a weak physical structure, which requires strengthening by one of the appropriate consolidants, whether acrylic, silicon, acrylic-silicon, or nano composites. In the past few years, nano composites used to strengthen the pottery objects. Some nano materials were added to acrylic and silicon polymers in order to improve their physicochemical and mechanical properties, where it achieved a significant improvement in the ability of those polymers to strengthen the pottery [13] . Pottery or glass 
pieces are subject to breakage and the loss of some parts due to burial soil [14] , weak internal structure and internal pressures impact [15], or as a result of pressures and external loads [16]. Such pieces need assembly and completion processes. These processes are complex technical techniques [17] .The adhesive and completion materials have varied based on their physical and chemical nature [18]. The materials used in cleaning, strengthening, assembling and completing have varied according to experimental studies in the field of treatment. Therefore, this study aims to present strategies of treatment of pottery artifacts extracted from Tell Al-Shobak in Qalyubia according to results of examinations, analyzes and damage manifestations proven by research.

\section{Study Materials And Methods}

\section{Study materials}

Three pottery samples were selected, including (2) pottery samples, as well as one sample of site soil. Those samples used in examinations and analysis that conducted in the research.

\section{Study Methods:}

\section{Visual Examination}

Visual examination is one of the important methods that show pottery archaeometric features and damage manifestations by using different lenses " 4 X: 6 X" or USB digital microscope [19].

\section{Examination by polarizing microscope}

Polarizing microscope used to study petrographic aspects and firing conditions, additives and damage of mineral components of archaeological pottery [20]. Thin section of pottery sherds were prepared for petrographic examination using polarizing microscope "Olympus BX51 TF japan attached with digital camera under magnification $4 \mathrm{X}$ up to $40 \mathrm{X}$ ". It conducted at faculty of Science, Cairo University.

\section{Examination by scanning electron microscope with EDX unit}

Scanning electron microscope describes surface morphology and damage aspects [21]. The pottery samples examined by JEOL JSM-840 and SEM Quanta 200 FEG, XTE 325/D8395, the operating conditions were "20 kV and $1 \times 10^{-9} \mathrm{~A}$ ". This examination carried out by an environmental scanning electron microscope equipped with an EDX unit at Geological Survey Authority in Cairo. 


\section{Analysis by X-Ray Diffraction Method}

X-ray diffraction analysis is one of the important methods that gives mineral composition of pottery, which helps to identify archaeometric features, and damage manifestations [22]. The device is Philips; the diffraction pattern is between " $4-70^{\circ} 2 \theta^{\prime \prime}$. The operating conditions carried out using $\mathrm{Cu}-\mathrm{K}$ a radiation $40 \mathrm{MA}, 45 \mathrm{kV}$, this analysis conducted at National Research Center in Cairo

\section{Thermal Analysis}

DTA analyses was performed using Shimadzu-simultaneous thermal analysis type DTA- 50 to determine the firing temperature of our samples and evaluate thermal materials characterization.it explains how individual minerals change during a gradual increase in temperature after heating the sample in approximately $1000^{\circ} \mathrm{C}[23]$.

\section{Results}

\section{Visual Examination:}

The visual examination of the pottery pieces proved presence of soil sediments, crystallization of salts, soot, fracture, breaking, fragments and loss of some parts (Fig. 1A - B).

\section{Polarizing Microscope}

Two pottery samples extracted from tell al-Shobak examined with polarized microscope. PLM first pottery sample shows quartz grains calcite, grog, plagioclase, iron oxides, and calcareous deposition (Fig. 2). PLM of the same sample also shows quartz grains, calcite, pyroxene, plagioclase, biotite, grog and iron oxides (Fig. 3).

PLM examination for another part shows semi-circular and sharp-angled quartz grains, as well as presence of grog, calcite, plagioclase, pyroxene, lime deposits and internal cracks in matrix rich in iron oxide (Fig. 4).

PLM of the second pottery sample shows semi-circular and acute-angled quartz grains, calcite, biotite and muscovite, polycrystalline quartz grains and iron oxide (Fig. 5). It also shows presence of semicircular and acute-angled quartz grains, as well as polycrystalline quartz grains, limestone powder, plagioclase, some internal cracks, and iron oxide (Fig. 6).

For the same pottery sample shows presence of polycrystalline quartz grains, limestone powder, plagioclase, biotite, muscovite, lime deposit and iron oxide (Fig. 7)

\section{Examination and analysis by SEM-EDX \\ Examination by Scanning Electron Microscope}


SEM Examination of the first pottery sample shows that the sample suffers from various damage aspects such as phenomenon of cracking, some stains, quartz grains, and peeling off slip layer ( Fig. 8a). SEM Examination also shows phenomenon of cracking, gaps and crystallization of salts (Fig. 8b).

SEM Examination of the second pottery sample shows presence of fractures, cracks, gaps ,exfoliation of slip layer and salt crystallization ( Fig. 9a).

SEM of the same sample also shows phenomenon of crystallization of salts, gaps, cracks and coarse quartz grains (Fig. 9b)

\section{Scanning Electron Microscope Analysis}

The results of EDX analysis of three pottery samples from tell Elshobak, Egypt clarified presence of carbon, oxygen, fluorite, nickel sodium, magnesium, aluminum, silica, Molybdenum, sulfur, chlorine, potassium, calcium, titanium, and iron oxides. These EDX analytical results for three pottery sample (Fig. 10a-d) and (Table 1).

Table 1

EDX analytical results of investigated pottery shards 


\begin{tabular}{|llllll|}
\hline & & S1 & & S2 \\
\hline Elemental Weight \% & Surface & core & surface & Core \\
$\mathrm{C}$ & 15.17 & 1.95 & 1.78 & 0.66 \\
$\mathrm{O}$ & 19.95 & 16.27 & 27.54 & 18.25 \\
$\mathrm{~F}$ & - & - & 0.63 & - \\
$\mathrm{Ne}$ & - & - & 0.32 & - \\
$\mathrm{Na}$ & 9.82 & 0.42 & 1.44 & 0.31 \\
$\mathrm{Mg}$ & 2.54 & 1.10 & 3.50 & 1.80 \\
$\mathrm{Al}$ & 5.16 & 10.33 & 8.31 & 1.50 \\
$\mathrm{Si}$ & 12.78 & 13.82 & 23.93 & 4.76 \\
$\mathrm{Mo}$ & - & 0.60 & - & - \\
$\mathrm{P}$ & - & - & - & - \\
$\mathrm{S}$ & 3.13 & - & 3.43 & - \\
$\mathrm{Cl}$ & 16.19 & 4.45 & 4.46 & - \\
$\mathrm{K}$ & 1.01 & 0.25 & 2.37 & 0.35 \\
$\mathrm{Ca}$ & 9.43 & 8.25 & 14.77 & 6.48 \\
$\mathrm{Ti}$ & 0.20 & - & 0.90 & 30.24 \\
$\mathrm{Fe}$ & 4.63 & 51.52 & 7.57 & 35.65 \\
\hline $\mathrm{CH}$ & & & &
\end{tabular}

\section{X-Ray Diffraction Analysis}

Three samples were analyzed, including two pottery samples and one sample from the soil of the archaeological site, where X-ray diffraction pattern of the first sample shows the presence of hematite, quartz, albite, calcite and gypsum as in figure (Fig. 11) and (Table 2) . X-ray diffraction pattern of the second sample confirmed presence of quartz, albite, calcite and gypsum as in figure ( Fig. 12) and (Table 2 ). The analysis of the third soil sample of tell al-Shobak in Qalyubia proved presence of quartz, albite and calcite, as in figure ( Fig. 13 ) and (Table 2 ) .It is clear from the results of the X-ray diffraction pattern that the soil is sandy clay rich in salt. 
Table 2

XRD analytical results of investigated pottery shards.

\begin{tabular}{|lllll|}
\hline Mineralogical Compositions & & pottery & Samples & \\
\hline Minerals & Chemical composition & $\mathrm{a}$ & $\mathrm{b}$ & $\mathrm{C}$ \\
& & & & soil \\
\hline quartz & $\mathrm{SiO}_{2}$ & 30.1 & 36 & 40.9 \\
\hline albite & $\mathrm{NaAlSi}_{3} \mathrm{O}_{10}$ & 42.9 & 43 & 33.4 \\
\hline calcite & $\mathrm{CaCO}_{3}$ & 8.1 & 5.2 & 25.7 \\
\hline hematite & $\mathrm{Fe}_{2} \mathrm{O}_{3}$ & 5.5 & - & - \\
\hline gypsum & $\mathrm{CaSO}_{4} \cdot 2 \mathrm{H}_{2} \mathrm{O}$ & 13.4 & 15.8 & - \\
\hline
\end{tabular}

\section{Differential thermal analysis}

Differential thermal analysis "DTA" of the first pottery sample showed minerals changes in firing temperature from $31.21^{\circ} \mathrm{C}$ to $79.60^{\circ} \mathrm{C}$., the minerals changes decreased from $109.80^{\circ} \mathrm{C}$ to $164.00^{\circ} \mathrm{C}$, the minerals changes also increased from $388.83^{\circ} \mathrm{C}$ to $726.78^{\circ} \mathrm{C}$, the stability of the mineral changes from $726.78^{\circ} \mathrm{C}$ to $1000^{\circ} \mathrm{C}$. The results of mineral changes indicated that the firing temperature might be about $726.78^{\circ} \mathrm{C}$, (Fig. 14). Differential thermal analysis "DTA" of the second pottery sample showed minerals changes in firing temperature from $294.72^{\circ} \mathrm{C}$ to $408.56^{\circ} \mathrm{C}$., the minerals changes increased from $479.89^{\circ} \mathrm{C}$ to $737.80^{\circ} \mathrm{C}$, the stability of the mineral changes from $737.80^{\circ} \mathrm{C}$ to $1000^{\circ} \mathrm{C}$. The results of mineral changes indicated that the firing temperature might be about $737.80^{\circ} \mathrm{C}$ (Fig. 15).

\section{Discussion Of Results}

The visual examination of the pottery pieces from tell el-Shobak in Qalyubia, Egypt showed that the pottery samples formed by potter wheel method. It also shows soot, salts, cracking, lost parts and surface sediments as shown in ( Fig. 1a-b). Damage aspects were due to heterogeneity of mineral components [24]. Some researchers attributed the damage to burial in the soil [25] .The exposure environment (post excavation) increases severity of damage [26]. Polarized microscope proved that the used clay is Nile clay due to presence of biotite, muscovite, pyroxene and plagioclase [27] as shown in ( Fig. 2:7). PLM examination confirmed presence of some additives such as sand, lime stone powder and grog, which are common materials in Egyptian pottery [28] as shown in ( Fig. 2:7). PLM examination also proved presence of surface treatment by slip layer. Sometimes, the ancient Egyptian used red wash [29]. The 
examination also showed presence of some internal cracks due to pressures and strains. Pottery texture was coarse for the first sample and medium to coarse for the second sample as in Fig. (2:7). The texture is shape and relationship of the granules to each other [30]. The texture varies according to clay, formation technique, surface treatment, and firing [31]. SEM Examination showed presence damage aspects, such as cracks, gaps, fractures, crystallization of salts and stains, as in shown in ( Fig. 8a-b \&9ab. (Cracks in our studied pottery are due to internal pressures and crystallization of salts [32]. SEM- EDX confirmed medium burning of the first pottery for presence of carbon dioxide with a high percentage $15.17 \%$ for the surface area and low percentage $1.95 \%$ for the core area. Good burning for the second pottery sample, where the percentage of carbon reached $1.78 \%$ for the surface and $0.66 \%$ for the core area. This indicates that the burning atmosphere was oxidizing atmosphere for pottery samples, as shown in (Table 1).SEM- EDX confirmed presence of calcite, chloride, and sulfate salts, where the percentage of chlorine in the first pottery sample reached $16.19 \%$ for the surface and $4.45 \%$ for the core. For the second sample, the percentage of chlorine reached $4.46 \%$ for the surface as shown in (Table 1). EDX also proved presence of calcium, where the percentage of calcium in the first pottery sample reached $9.43 \%$ for the surface and $8.25 \%$ for the core. For the second sample, the percentage of calcium reached $14.77 \%$ for the surface and $6.48 \%$ for the core as shown in (Table 1 ). The percentage of sulfur in the first pottery sample reached $3.13 \%$ for the surface, while the percentage of sulfur in the second pottery sample reached $3.43 \%$ for the surface, which confirms presence of chloride and sulfate salts as shown in (Table 1). The crystallization of salts is one of the most important manifestations of damage because pottery artifacts is a hygroscopic material that absorbs saline water from the soil [33].XRD proved

presence of calcite as one of the temper additives [34]. The analysis also proved presence of gypsum and carbonates due to burial soil [35]. XRD analysis also revealed presence of albite, quartz and calcite in the archaeological site sample, which confirms that the soil is calcareous clay soil as shown in (Table 2). Differential thermal analysis "DTA" of the first pottery sample showed the firing temperature was $726.78^{\circ} \mathrm{C}$ for the first pottery, where the hydroxyl group of mechanical combined water for clay was lost at firing temperature from $31.21 .{ }^{\circ} \mathrm{C}$ to $79.60^{\circ} \mathrm{C}$. The minerals changes increased by hydroxyl group loss of chemical combined water of clay, burning and oxidation of organic matter from $109.80^{\circ} \mathrm{C}$ to $164^{\circ} \mathrm{C}$ and then the minerals changes were significantly increased due to decomposition of carbonate into $\mathrm{CaO}$ and Co2, organic residues and chlorides from 388.83 to726.78 (Fig. 14) .for the second pottery, the firing temperature was $737.80^{\circ} \mathrm{C}$, where the hydroxyl group of mechanical and chemical combined water of clay, burning and oxidation of organic matter from $294.72^{\circ} \mathrm{C}$ to $408.56^{\circ} \mathrm{C}$ and then the minerals changes were significantly increased due to decomposition of carbonate into $\mathrm{CaO}$ and $\mathrm{Co} 2$, organic residues and chlorides from $479.89737 .80^{\circ} \mathrm{C}$ (Fig. 14) [36] .

\section{Treatment and maintenance}

The study of the various examinations and analyzes to our studied pottery artifacts from tell El-Shobak in Qalyubia, Egypt proved presence of soil sediments, as well as chloride, sulfate salts, and soot. Pottery objects suffer from breaking and loss of some parts of body 
Pottery pieces characterized by weakness and lack of durability. According to damage conditions, results of examinations and analyzes and scientific studies in this field. Restoration, treatment and maintenance processes applied on our studied pottery artifacts.

\section{Recording and Documentation}

The pottery objects (the vessel and plate) excavated from tell El-Shobak in Qalyubia, Egypt were photographed as shown in (Fig. 16a,b) to determine damage aspects or deterioration state before treatment..

\section{Cleaning}

The pottery pieces cleaned of soil deposits mechanically using various brushes. The sediments that were highly adherent to the surface were cleaned using metal scalpels. The cleaning method was carried out from top to bottom not to scratch the pottery body [37]. It has given positive results, as shown (Fig. 17a-f ) .

Chemical cleaning carried out in order to clean the various soil deposits using organic solvents. A mixture of acetone and toluene in a ratio of 1:2 respectively was prepared; chemical cleaning for our studied objects done locally for each piece separately according to [38]. Soot sediments was removed using hydrogen peroxide $20 \%$ [39], the calcareous sediments were cleaned using EDTA, that applied as a poultice [40], cleaning results as shown in figure ( Fig. 18a-f)

\section{Removal of Salts}

The salts were removed mechanically using brushes and scalpels .cleaning was done under lenses "6X" not to scratch the pottery according to [41]. Then, this was followed by making poultice of distilled water to remove soluble salts such as halite salts, according to [42]. EDTA poultice applied to remove calcareous deposits of carbonates and sulfates salts [43].

\section{Consolidation}

The pottery artifacts extracted from Tell el-Shobak in Qalyubia were strengthened using nano silica $1 \%$ according to (Saad, 2018) [44]. Poultice method was applied in strengthening process according to (Dei 2013) [45].

\section{Assembling}

The initial assembly process for broken pottery started to find out the places of fracture of pottery sherds according to (Elghareb, 2007) [46].

Then, the pottery sherds were assembled using paralloid B 72 dissolved in toluene $50 \%$ [47]. Assembling results as in (Fig. 19a, c).

\section{Filling Gaps}


After the assembly process, it was noticed that the pottery artifacts were missing some parts.

Replacement was applied using a mixture of microballoon and Pottery powder in a ratio of 2: 1. First, alumina paper applied under the missing part to match the lost part. Second, completion material was prepared, which is a mixture of microballoon and Pottery powder in a ratio of 2: 1 . Third, the completion material applied according to (Saleh et al. 2020) [48]. After an hour, it was shaped and polished using various molding tools. Thus, the pottery pieces restored the artistic and archaeological form that it was before burial in the soil. Results shown in (Fig. 20a, c).

After replacement of our studied objects, the pottery artifacts were strengthened, protected and isolated using Paralloid B 82 (3\%) by brushing. Pottery artifacts were ready to museum display (Fig. 21a, b).

\section{Conclusion}

The research has reached a set of results of great importance in identifying the archaeometric features at tell El-Shobak in Qalyubia. Clay was Nile clay. The additives were sand, grog, and limestone powder. Shape technique used in manufacture of pottery pieces is potter-forming technique. Surface treatment is of slip layer. Burning atmosphere was an oxidizing atmosphere. Research paper also proved that most of the pottery monuments from tell el-Shobak in Qalyubia suffer from damage aspects such as soil deposits, stains, fracture and loss of some parts, Salts crystallization " chlorides, sulfates, carbonates", and weakness and lack of durability of pottery pieces. The research found using of a mixture of acetone and toluene at a ratio of 2:1, respectively to remove clay soil deposits. Using of hydrogen peroxide $20 \%$ to remove soot. EDTA used to clean lime deposits. Nano-silica at a concentration of $1 \%$ in strengthening archaeological pottery by spraying method. Using a mixture of microballoon and pottery powder at a ratio of 2:1, respectively, to complete the pottery objects. It is preferable to display the pottery artifacts in the museum at a temperature of $20^{\circ} \mathrm{C}$ and a relative humidity of 55:60percentage.

\section{Declarations}

\section{Acknowledgment}

I would like to extend my sincere thanks and appreciation to Dr. Sameh Al-Tayer, Faculty of Science, Cairo University for his efforts in examination and analysis of our pottery samples. I also extend my thanks and gratitude to the restoration specialists and antiquities inspectors in Qalyubia, my special thanks and gratitude to Mr. Mohamed Hussein, conservator in grand Egyptian museum for his efforts and help.

\section{Declaration of Competing Interest:}

I disclose that I have no any financial and personal relationships with other people or organizations that could inappropriately influence my work reported in this paper, No conflict of interest exits in the submission of this manuscript. 


\section{Author contributions:}

Walid Elghareb, author of this paper had designed, directed, and carried out this study, in addition to examinations, analysis, discussion of the results and wrote the paper.

\section{Data availability:}

the datasets of my research used and/or analyzed during our current research (Structure Features, Damage, and Treatment of two pottery artifacts from tell elshobak, Qalyubia, Egypt) may be made available from the author on reasonable request.

\section{Funding:}

The author did not receive funding from any institution or organization for my research. No funding was received for conducting my research. No funds, grants or other support was received.

\section{References}

1. Nour El-Din A. Sites of ancient Egyptian antiquities from the earliest times until the end of Egyptian dynasties ages, part one, Lower Egypt. Cairo: Al-Aqsa for printing and publishing; 2008. p. 280.

2. El-Tally K, The eighth district of Lower Egypt, Ph.D. thesis, Faculty of Arts, Banha University, (2001)116.

3. Salem S, The eighth region of lower Egypt in the second intermediate period, archaeological study, PhD thesis, Faculty of Arts, Tanta University, 2001:20-28.

4. Helmy M, Tell Attrib from the Old Kingdom to the Roman Era, Master Thesis, Faculty of Archeology, Cairo University,(2007) 58-65.

5. Ali M, Sh.Omar. Analytical investigation of deterioration aspects in mihrab of madrasa Gawhariyya of Al-Azhar mosque, Egypt. Egyptian Journal of Archaeological Restoration Studies. 2021;11(1):9.

6. JW. Łukaszewicz. Stone in architecture and sculpture, deterioration and conservation, Egypt, Egyptian Journal of Archaeological Restoration Studies, 10 (2) (2020) 103.

7. Zidan Y, El Hadidi N, Fawzi M, Rabie M. The effect of Carbogel Poultices on pine wood, Egypt. Egyptian Journal of Archaeological Restoration Studies. 2020;10(2):113.

8. Orabi AE, Abu Elyameen A. Analytical Study and treatments of the decayed mural painting at Athribis in Sheikh Hamad temple ,Sohag, Egypt, SHEDET, 7(2020) 238.

9. Kaye B, David G, Hamilton C, Morphet K. Super Critical Drying: Anew Method for Conserving Water logged Archaeological Materials. Stud Conserv. 2000;45(4):233.

10. Gibson BM. Methods of Removing White and Black Deposits from Ancient Pottery. Stud Conserv. 1971;16(1):18-22. 
11. Bogle LK, The Conservation of a Collection of Fired Damage Ceramics in The Conservation of Glass and Ceramics, edited by Tennent, N.H., London, (1999) 151.

12. Berti D, Cleaning III: Emulsions and Microemulsions in Nanoscience for the Conservation of Works of Art, edited by Piero Baglioni and David Chelazzi, Royal Society of Chemistry, Cambridge, (2013)200.

13. Darienzo L. New Polymeric Nanocomposities For Improving The Protective And Consolidating Efficieng Of Tuff Stone, Journal Of culture Heritage,(2008)253-260.

14. T. Rasha Hamad, using of fiberglass to consolidate complementing materials in archa eological glass: experimental study, SHEDET, 7(2020) 298.

15. Mohamed S, Analytical study of Techniques of Archeological Pottery in Sinai with treatment and conservation of some selected objects, MA, Conservation dept., Faculty of Archaeology, Fayoum Univ., (2019)72.

16. M.Mohamed, A comparative study of the types of pottery and ceramics during different ages in Egypt with the restoration and maintenance of antique pottery pieces, MA, Department of Restoration, Faculty of Archeology, Cairo University, (1991) 87-88.

17. Newey G, Adhesives In Science Forconservators, London, (1987) 13-15.

18. Williams N, Porcelain, RePair And Restoration, London, (1983) 49-50.

19. Adel G, Mahmoud, Elserogy A. Deterioration and conservation of an Assyrian Bronze kneading bowl. SHEDET. 2020;7:253.

20. Abdelmegeed M. Modified mud bricks for strengthening historic earthen structures: towards sustainable and green restoration. SHEDET. 2020;7:266.

21. Mabrouk N, Investigation and analysis of two Coptic textile fragments in the agricultural museum in Egypt, SHEDET, 7,(2020) 283.

22. El-Badry A. Deterioration mechanisms affecting the bricks used in the building of water wells at karnak temples, Luxor, Egypt. Egyptian Journal of Archaeological Restoration Studies. 2019;9(1):13.

23. Matějkováa K. and H.Stoksikb, Contribution of scientific analyses to the Archaeological Assessment of pottery production in Turnov, Czech Republic, journal of interdisciplinaria archaeologica natural sciences in archaeology. (IANSA). 2011;2(2):125-38.

24. W.Elghareb,,Archaeometric Investigation of Two Corroded Glass Wares in Tel El-kharoba, North Sinai, Egypt: Case Study,American International Journal of Research in Formal, Applied \& Natural Sciences,24(1)(2018)22-31.

25. Mohamed S, Study of Technology Treatment and Conservation of Faience Ushabti Statutes Kept in Stores and Preparing Them for Museum Display: Applied on Selected Objects, Master thesis, Conservation department, Faculty of Archaeology, Cairo University (2013)111-112.

26. El-Gohary M. Effective roles of some deterioration agents affecting Edfu royal birth house "Mammisi". IJCS. 2015;6(3):349-68.

27. Elghareb W. Archaeometry Study and Deterioration of Some Pottery Objects of Suhail Island in South Western Aswan, Egypt: Case Study. Current Science International. 2018;7(2):176-90. 
28. El-Gohary M, El-Ghareb W, Saad M. Damage quantification of archaeological pottery in Sheikh Hamad "Athribis" Sohag- Egypt. Ceramics International Journal. 2019;45(14):17611-9.

29. Shepared A. Ceramics for the Archaeologists, institution of Washington. Braun-Brumfield, Inc., (1981) 55.

30. Hamdan M, Garcia M, Nogues M, Hassan F, Flower A, Aly M, A.Senussi,and. Ibrahim E. Ancient Egyptian pottery from the subsurface flood plain of the Saqqara-Memphis area: its mineralogical and geochemical implications, Archaeometry, 56 (6) (2014) 987-1008.

31. Arnold D. Techniques and traditions of manufacture in the pottery of ancient Egypt. In: Arnold D, Bourriau,) J. An introduction to Ancient Egyptian pottery (ed. Egypt: IFAO, Cairo; 1993. pp. 2-7. in, .

32. Al-Qadhi M. Analytical Study of Monumental Yemenian Pottery and Conservation Methods: Applied on Some Selected Object from Different Site in Yemen, Master thesis, Conservation department, Faculty of Archaeology, Cairo University,(2014)151-152.

33. A.Paterakis, and Steiger M. Salt efflorescence on pottery in the Athenian Agora: a closer look. Studies in Conservation. 2015;60(3):172-84.

34. Rice P. Pottery Analysis: A Sourcebook, second ed., Chicago University Press. Ltd.,London,2015:160168.

35. El-Gohary M. Investigation on limestone weathering of El-Tuba minaret El- Mahalla, Egypt: a case study. Mediterranean Archaeology Archaeometry. 2010;10(1):61-79.

36. Elghareb W, Determination study of firing temperature degree for some of pottery vessels as a scientific basis for diagnosis of their phenomena of deterioration (Tel al-samara - pre dynastic - Case Study, JGUAA, (2016) 461.

37. Abd-Allah R, Al-Muheisen Z. \& S.Al-Howadi, Cleaning strategies of pottery objects excavated from Khirbet and Hayyan, Jordan: Four Case Studies. Mediterranean Archaeology Archaeometry. 2010;10(2):97-110.

38. Cronyn J. The elements of archaeological conservation. first ed. London: Routledge; 1996. pp. 20510.

39. S.Buys, and Oakley V. The conservation and restoration of ceramics. Oxford: Butterworth; 1993. pp. 193-4.

40. paul A. Influence of complexing agents and nature of the buffer solution on the chemical durability of glass. Part I. Theoretical discussion. Journal of Glass Technology. 1978;19:162-5.

41. C.Sease, Conservation manual for the field Archaeologist, 3rd edition, California, (1994)118-119.

42. Abd-Allah R. Stabilization and treatment of corroded glass objects. displayed in the museum of Jordanian heritage. Mediterranean Archaeology Archaeometry. 2007;7:19-28.

43. N. Abdel Rahim Restoration of an archaeological ceramic jar from Mamluk. period (1250-1517a.c.), al-fustat, Egypt: an analytical. study. Egyptian Journal of Archaeological Restoration Studies. 2016;6(1):11. 
44. Saad M, Usage of nano materials in the conservation of archaeological pottery: an experimental applied study on some excavated objects from El-Sheikh Hamd-Sohag, Master thesis, Conservation department., Faculty of Archaeology, Sohag University,(2018)315-316.

45. L. Dei Conservation treatments: cleaning, consolidation and protection, In: Baglioni P, Chelazzi D, editors. Nanoscience for the conservation of works of art. The Royal Society of Chemistry,(2013) pp. 77-92.

46. W.Elghareb, The scientific evaluation of effect of techniques of manufacture of Pottery Objects on rates of their deterioration in some different archaeological sites, Ph.D., Conservation department., Faculty of Archaeology, Cairo University(2007) 106.

47. Koob S. The use of Paralloid B-72 as an adhesive: its application for archaeological ceramics and other materials. Stud Conserv. 1986;31:7-14.

48. Saleh H, Abdelbar M, Sabry W, Ali A. Experimental study of gap filling of ancient completely corroded copper bowl via nano polymers. international journal of conservation science. 2020;11(1):97-108.

\section{Figures}
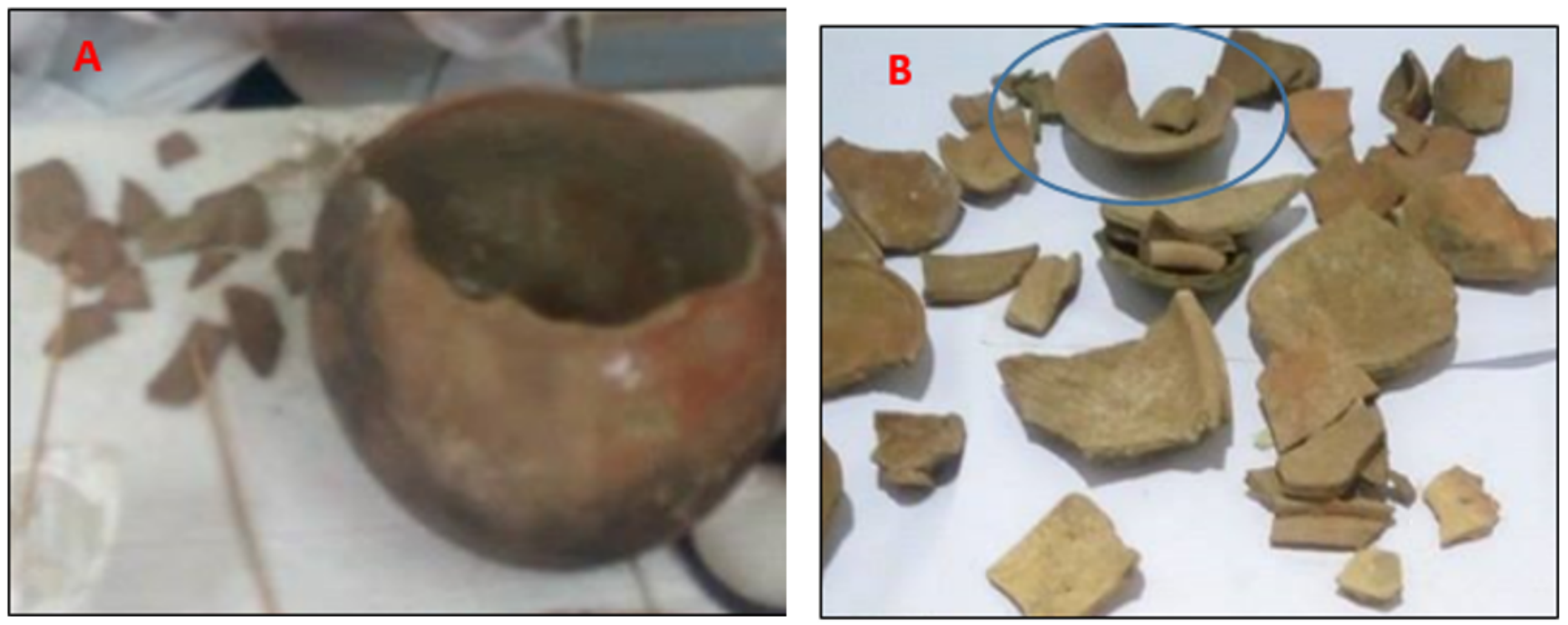

\section{Figure 1}

represents the pottery objects, Tell Al-Shobak, Qalyubia, A: pottery vessel, B: plate 


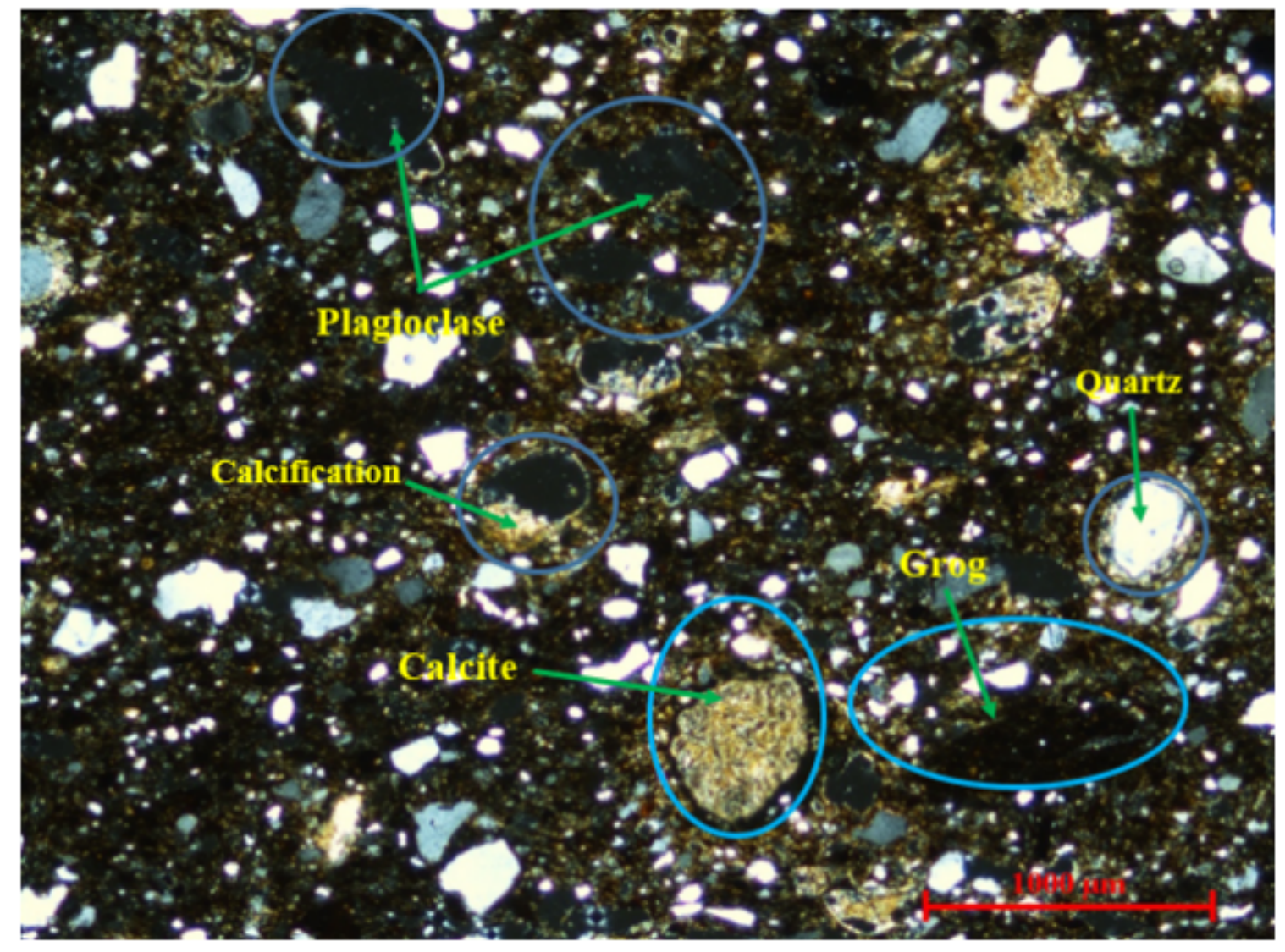

Figure 2

PLM examination of the first pottery sample shows quartz grains calcite, grog, plagioclase, iron oxides, and calcareous deposition (10X - CN) 


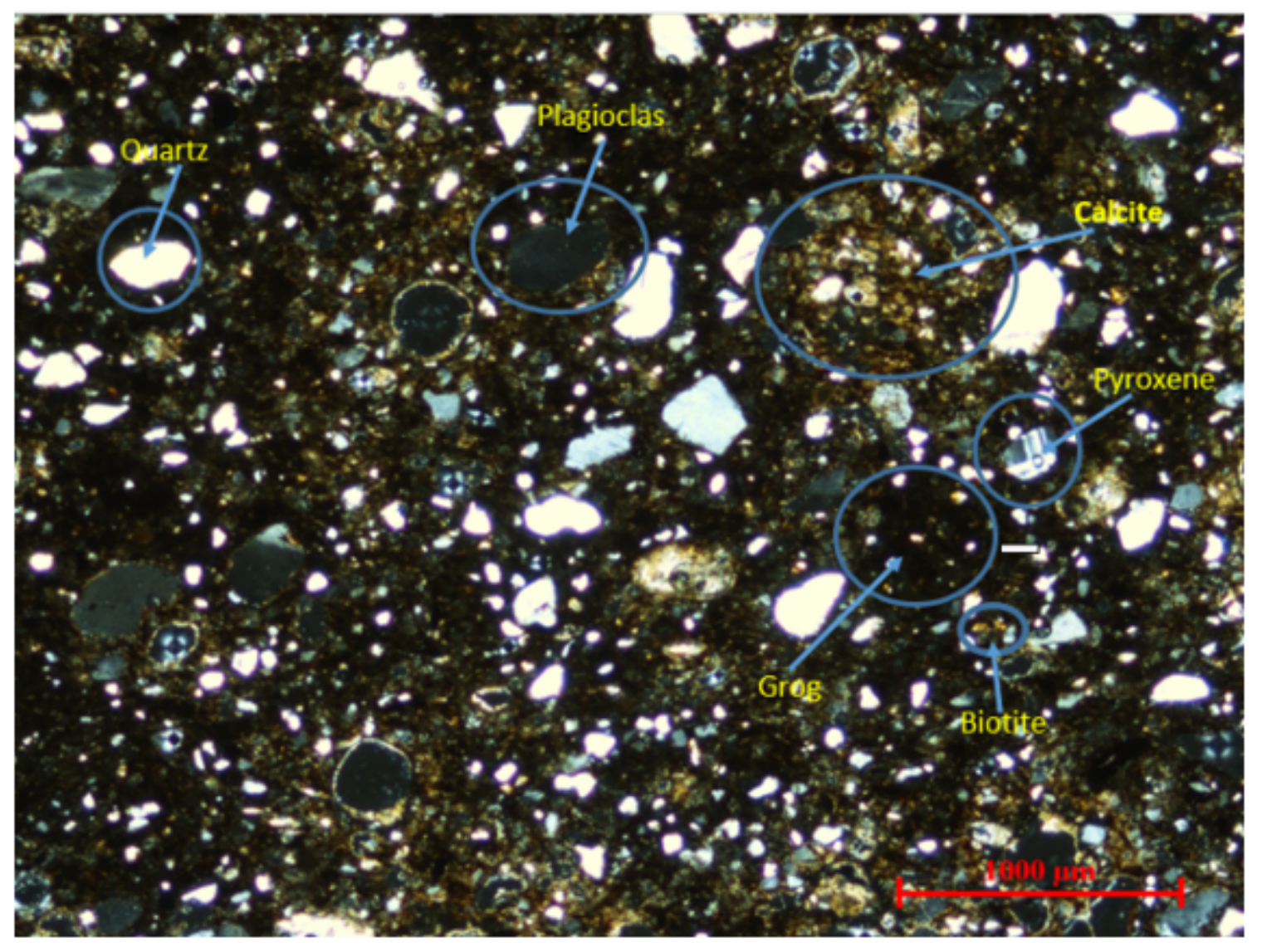

Figure 3

PLM examination of the same pottery sample shows quartz grains, calcite, pyroxene, plagioclase, biotite, grog and iron oxides $(10 \mathrm{X}-\mathrm{CN})$ 


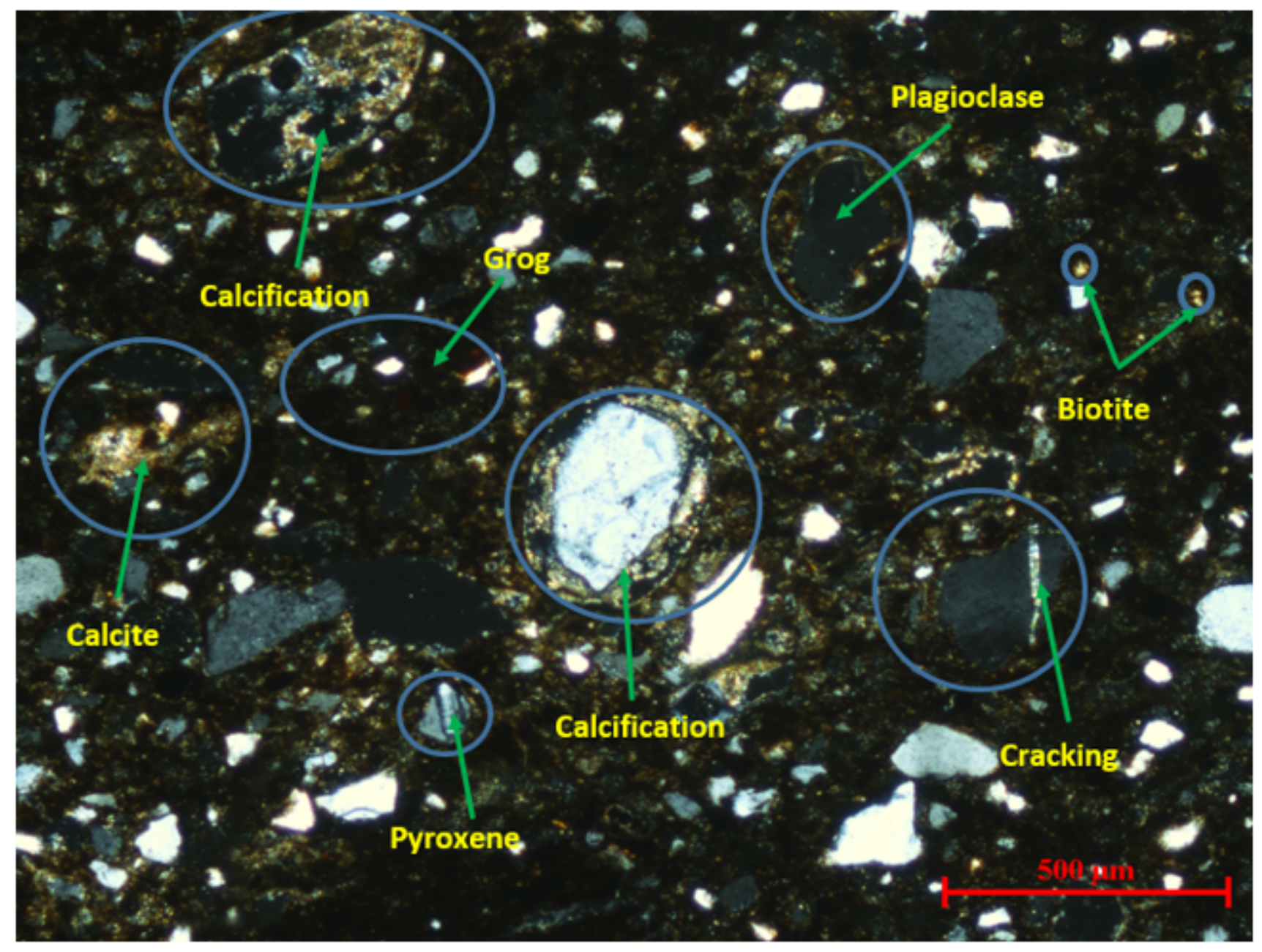

\section{Figure 4}

PLM examination of another part pottery sample shows quartz grains, grog, calcite, plagioclase, pyroxene, calcareous deposits and internal cracks in matrix rich in iron oxide (10X - CN) 


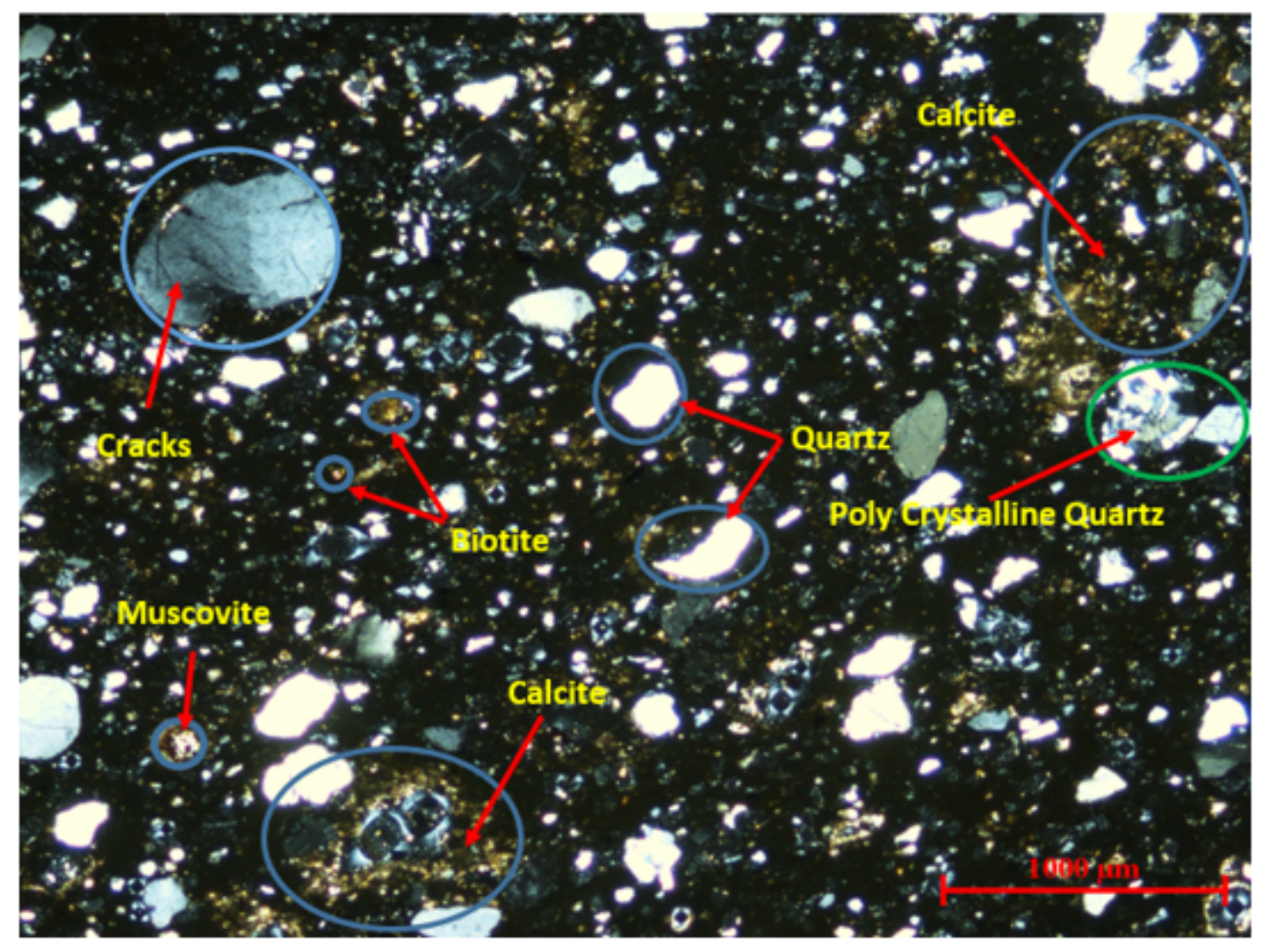

Figure 5

PLM examination of the second pottery sample shows semi-circular and acute-angled quartz grains, calcite, biotite and muscovite, polycrystalline quartz grains and iron oxide (10X - $\mathrm{CN}$ ) 


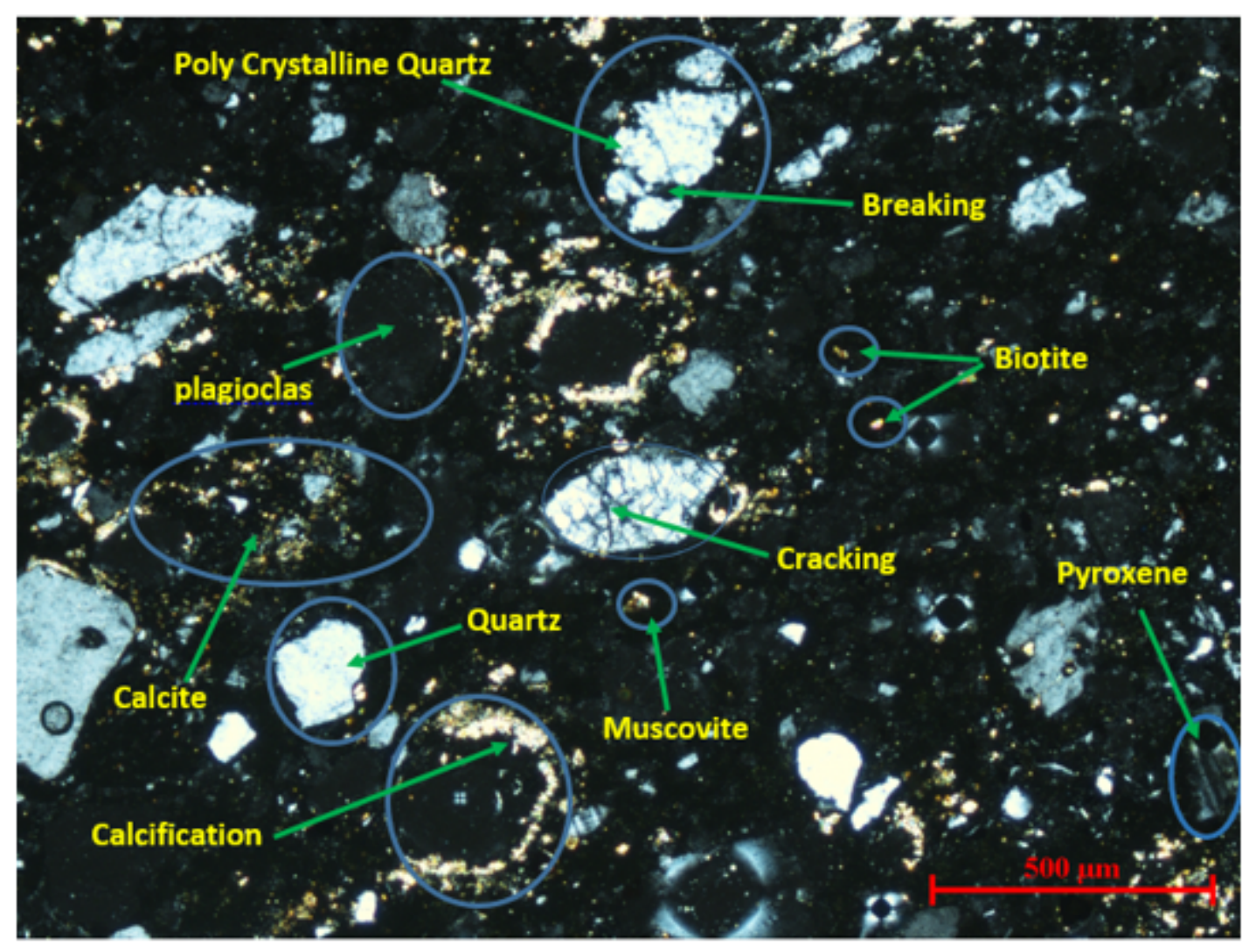

\section{Figure 6}

PLM examination of the same sample shows semi-circular and acute-angled quartz grains, polycrystalline quartz grains, limestone powder, plagioclase, some internal cracks, and iron oxide (10X $\mathrm{CN})$ 


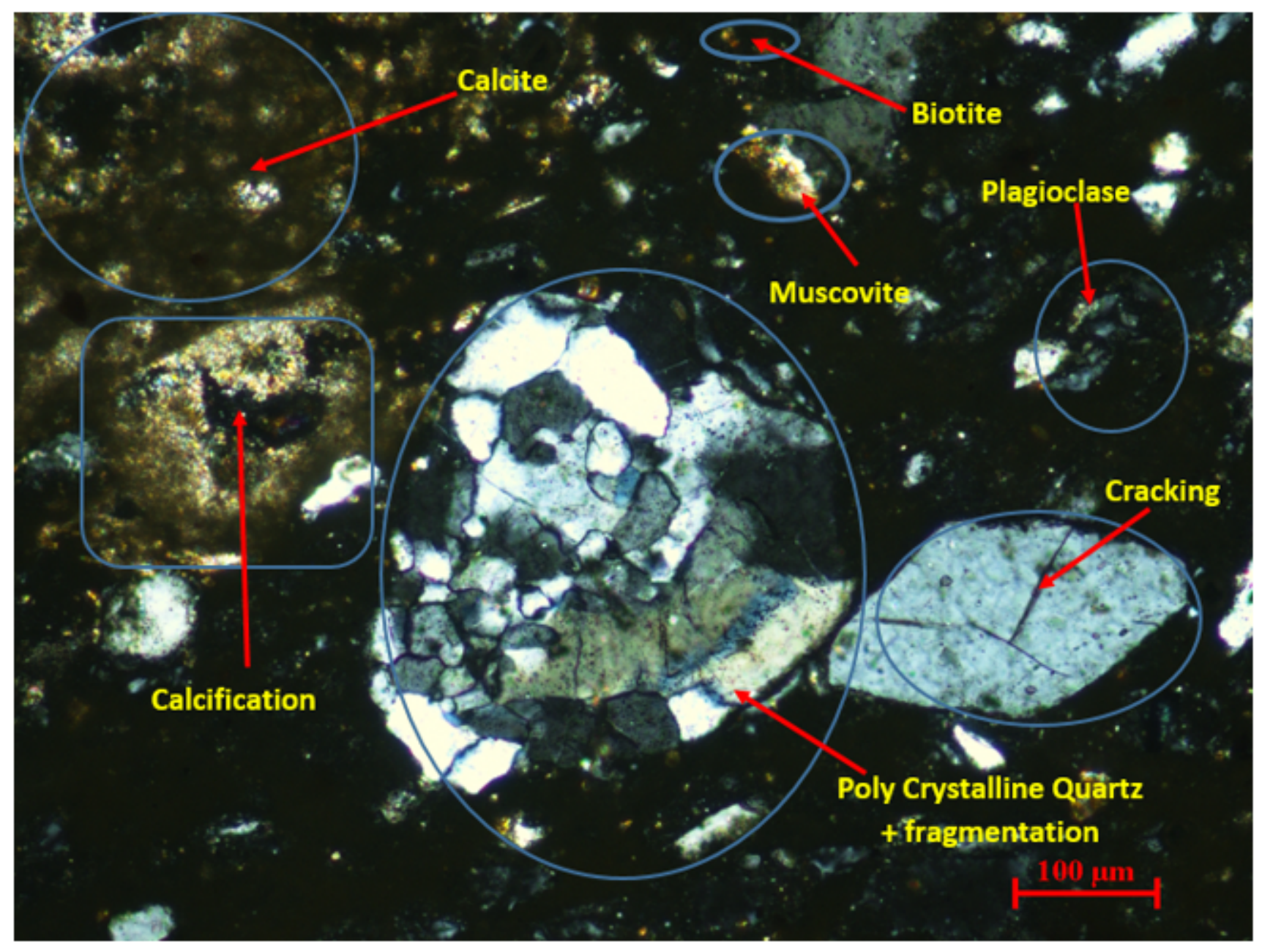

Figure 7

PLM examination of another part pottery sample shows polycrystalline quartz grains, limestone powder, plagioclase, biotite, muscovite, lime deposit and iron oxide (20X - CN) 

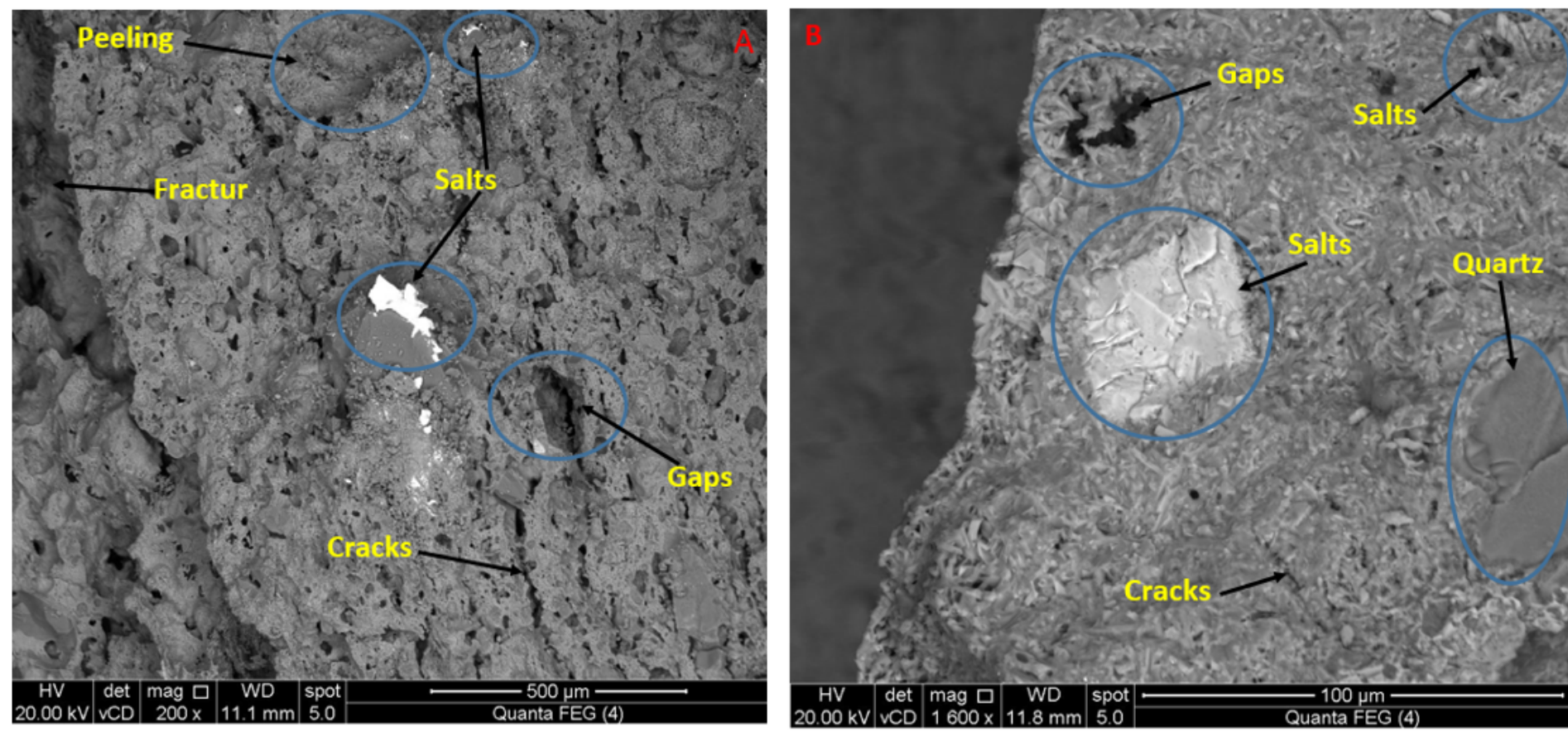

\section{Figure 8}

SEM photomicrograph of the first pottery sample, a: cracking, quartz grains, peeling, salts, and fracture, $b$ : cracking, gaps and crystallization of salts, accidently quartz grains
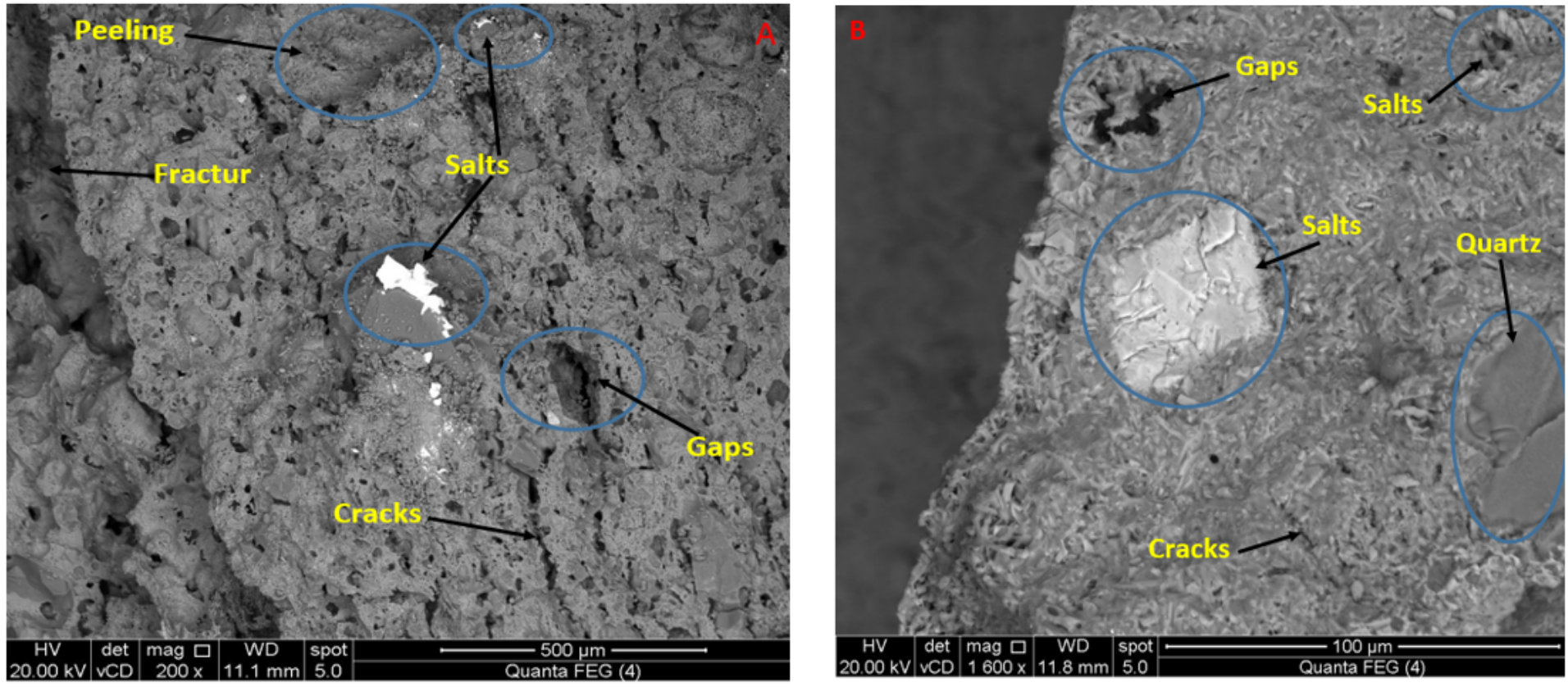

\section{Figure 9}

SEM photomicrograph of the second pottery sample, a : cracking, gaps, peeling, salts, and fracture, $b$ : cracks, gaps and crystallization of salts, accidently coarse quartz grains 

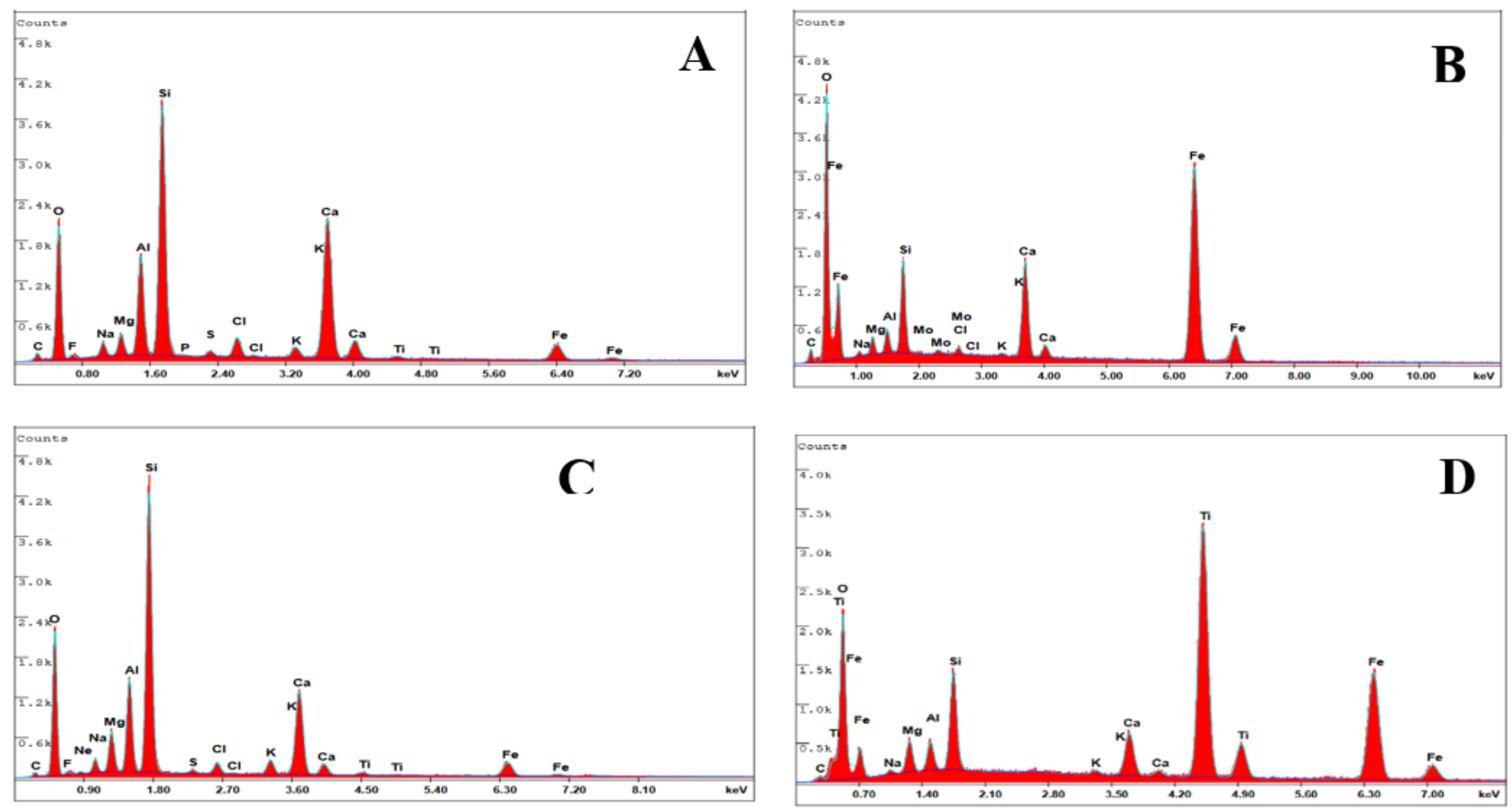

Figure 10

EDX analysis, a-b: first pottery, c-d: Second pottery,

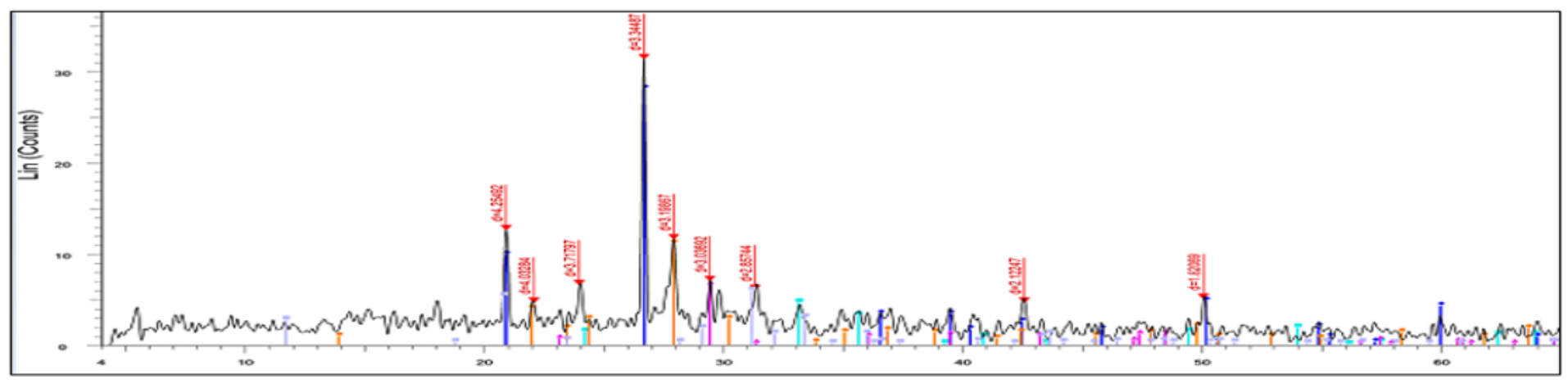

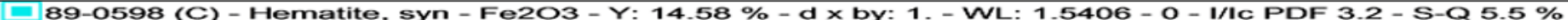

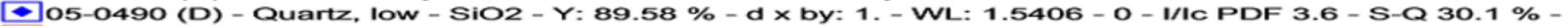

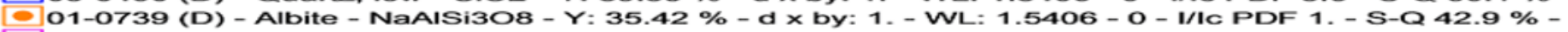

A 88-1808 (C) - Calcite - Ca(CO3) - Y: 20.83\% - d X by: 1 . - WL: 1.5406 - 0 - 1/lC PDF 3.1 - S-Q 8.1 \% -

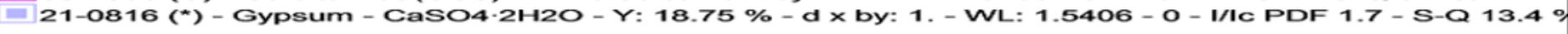

\section{Figure 11}

represents XRD pattern of the first pottery sample tell Al-Shobak, Egypt 


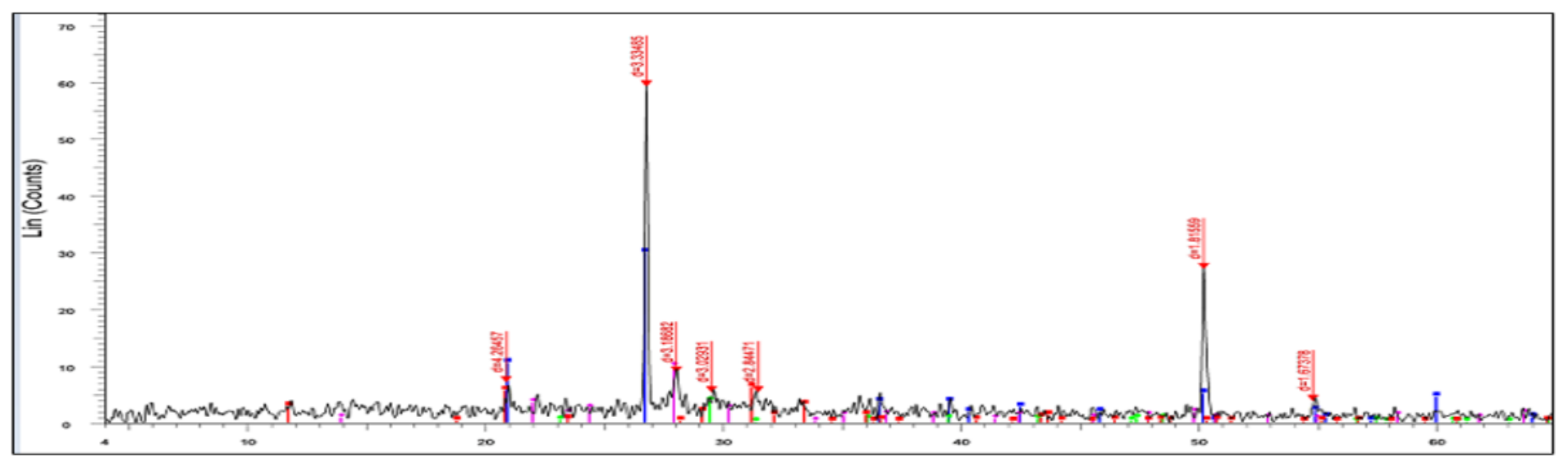

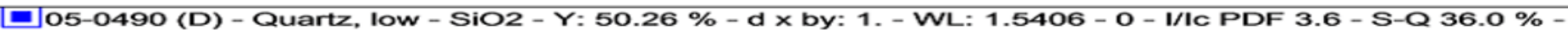

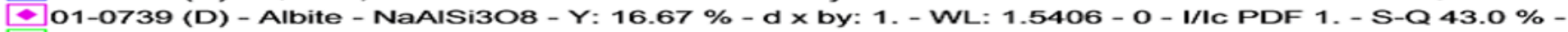

- 88-1808 (C) - Calcite - Ca(CO3) - Y: 6.25\% - d X by: 1. - WL: 1.5406 - O - I/IC PDF 3.1 - S-Q 5.2 \% -

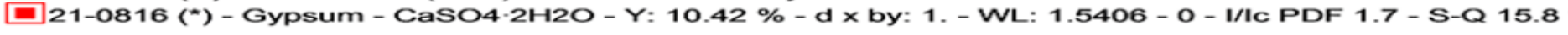

\section{Figure 12}

represents XRD pattern of the second pottery sample, tell Al-Shobak

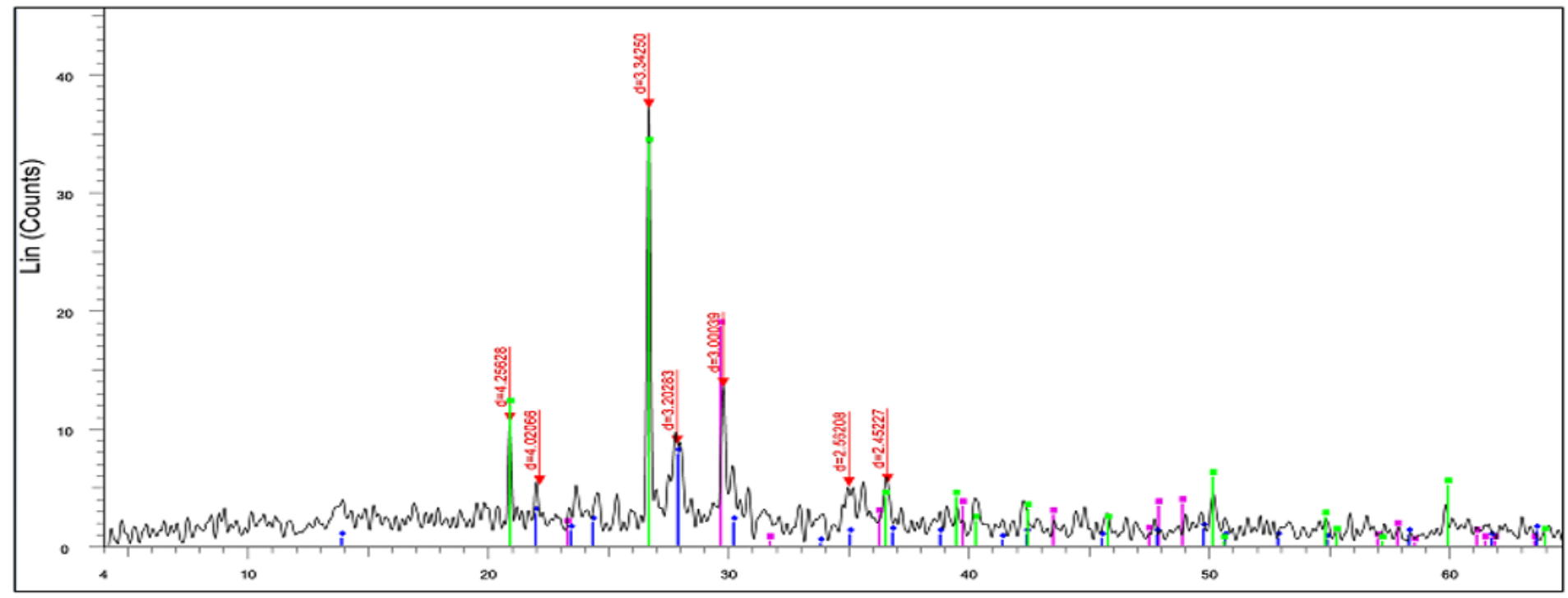

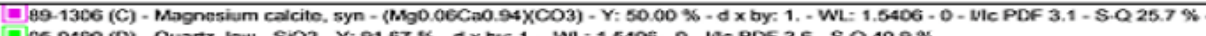

= 06-0450 (D) - Quart, low - SiO2 - Y: 91.67 \$ - đ X by: 1. - WL: 1.5406 - 0 - Vlc PDF 3.6 - S-O $40.9 \%$.

- 01-0739 (D) - Albite - NaAISU3C8 - Y: 20.83 \% - đ X by: 1. - WL: 1.5406 - 0 - NIC PDF 1. - S-0 33.4 \% -

\section{Figure 13}

represents XRD pattern of soil sample, tell Al-Shobak, Egypt 


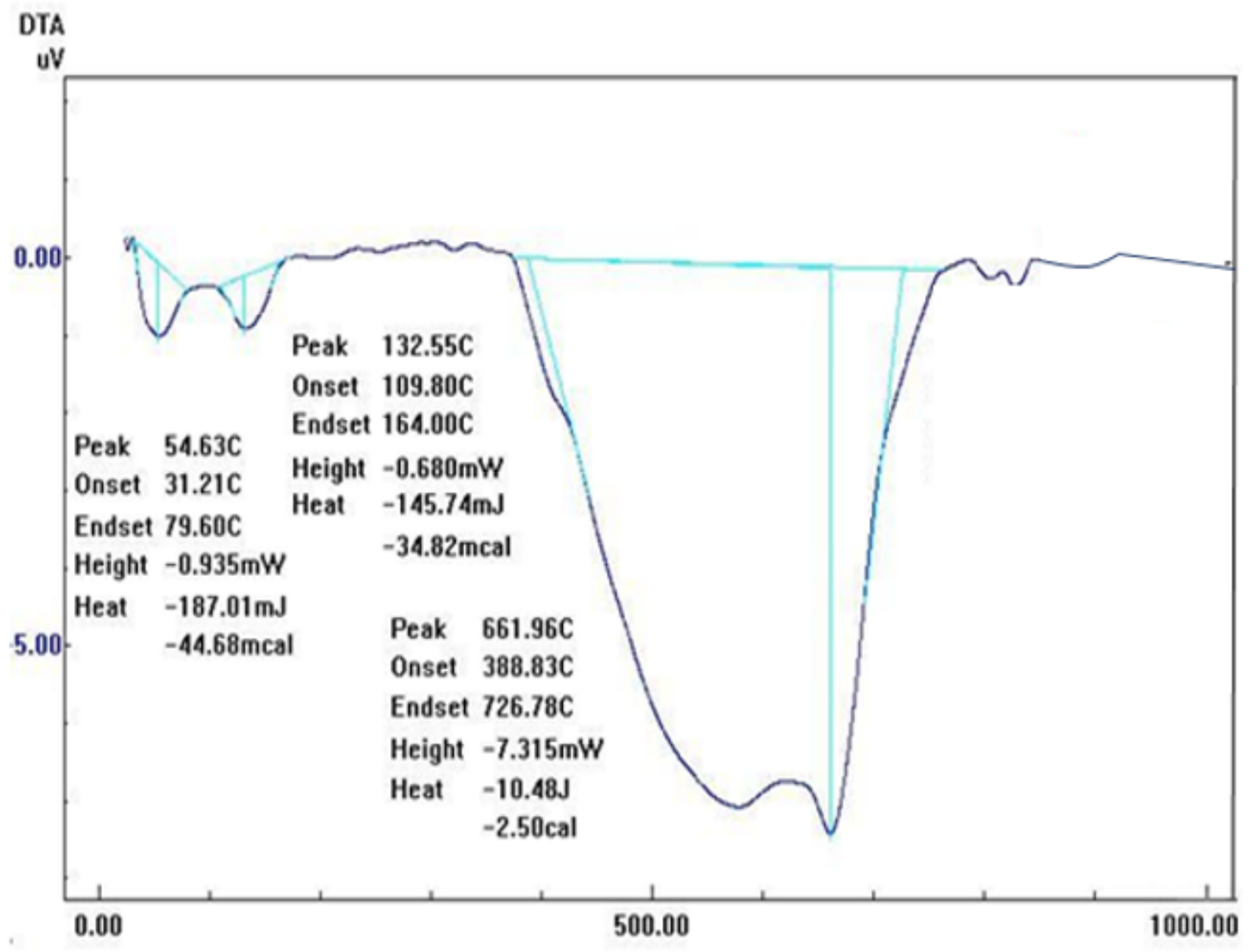

Figure 14

DTA pattern of the first pottery sample, tell elshobk, Egypt 


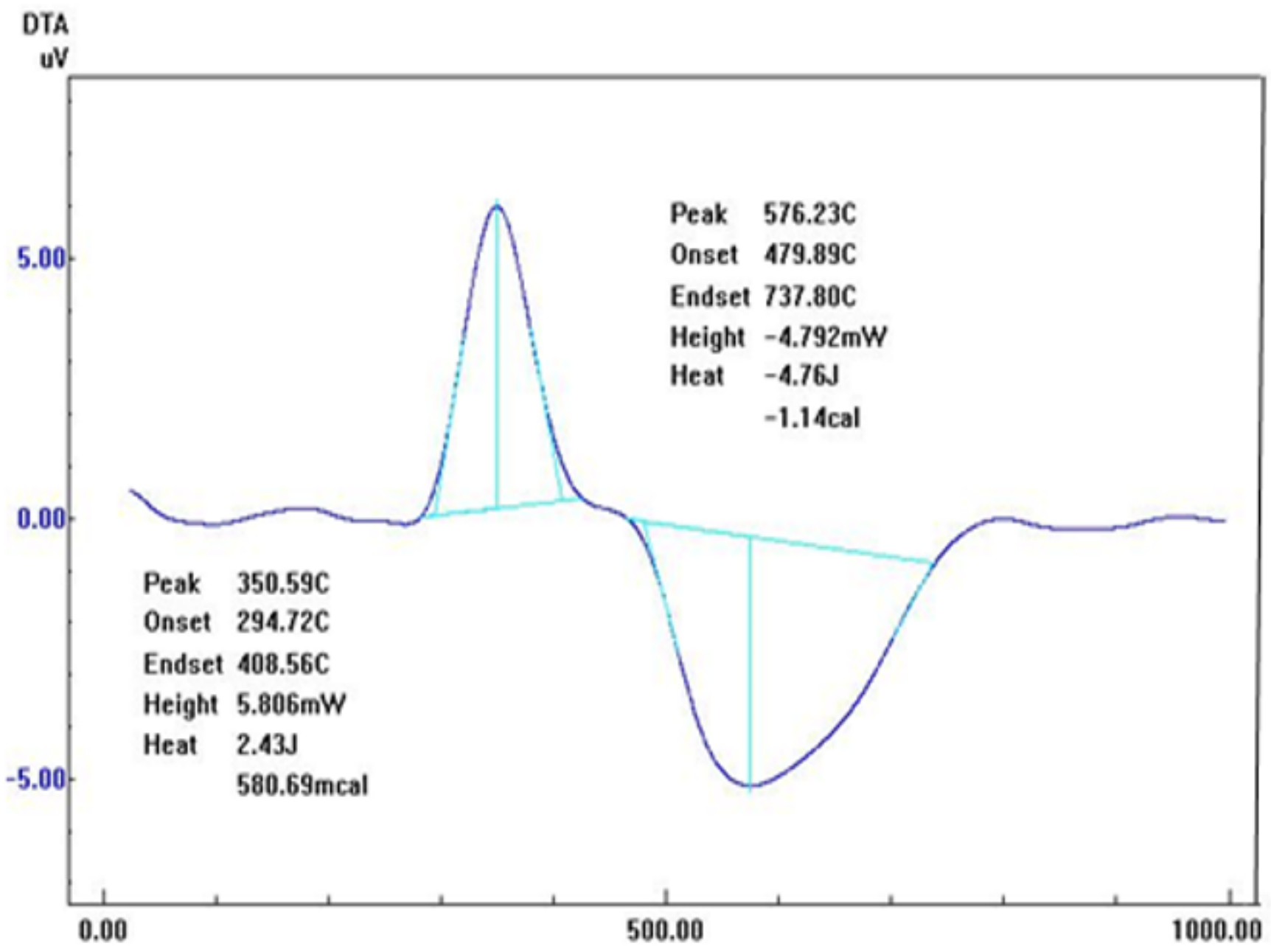

Figure 15

DTA pattern of the second pottery sample, tell elshobak, Egypt
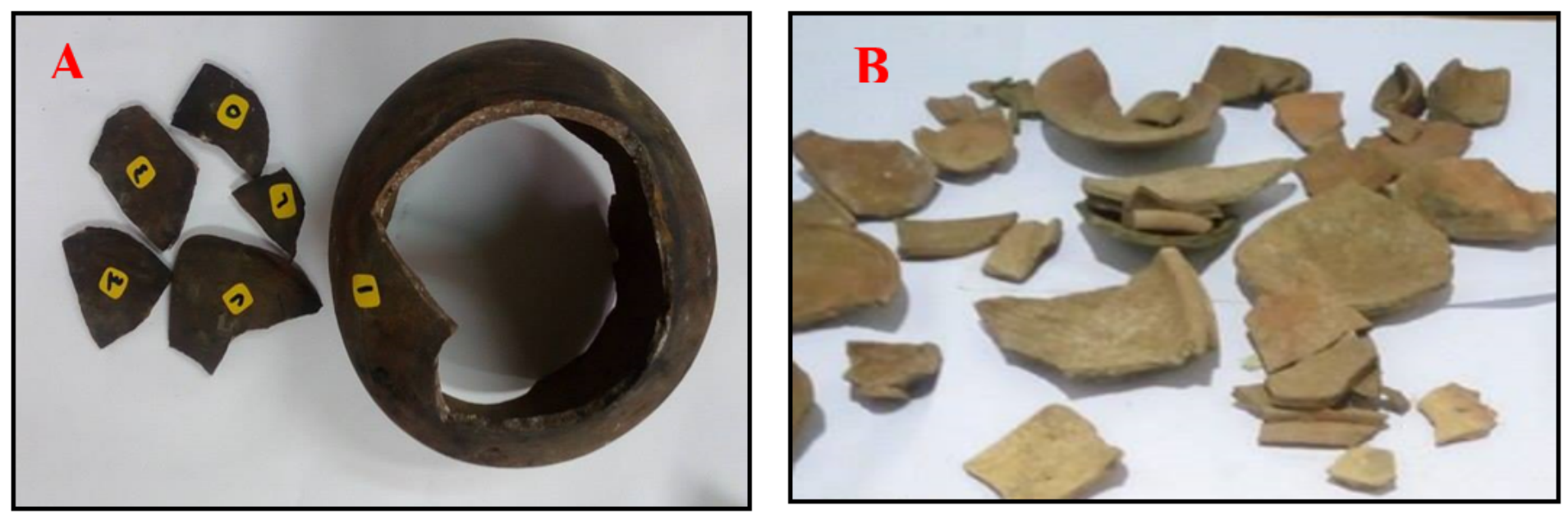

Figure 16

represents pottery artifacts "Case Studies" a: the first object, b: the second object 


\section{Figure 17}

represents cleaning of pottery artifacts, a: before cleaning, b: during cleaning, c: after mechanical cleaning of the first object, d: the second object before cleaning, e: during cleaning, f: after mechanical cleaning
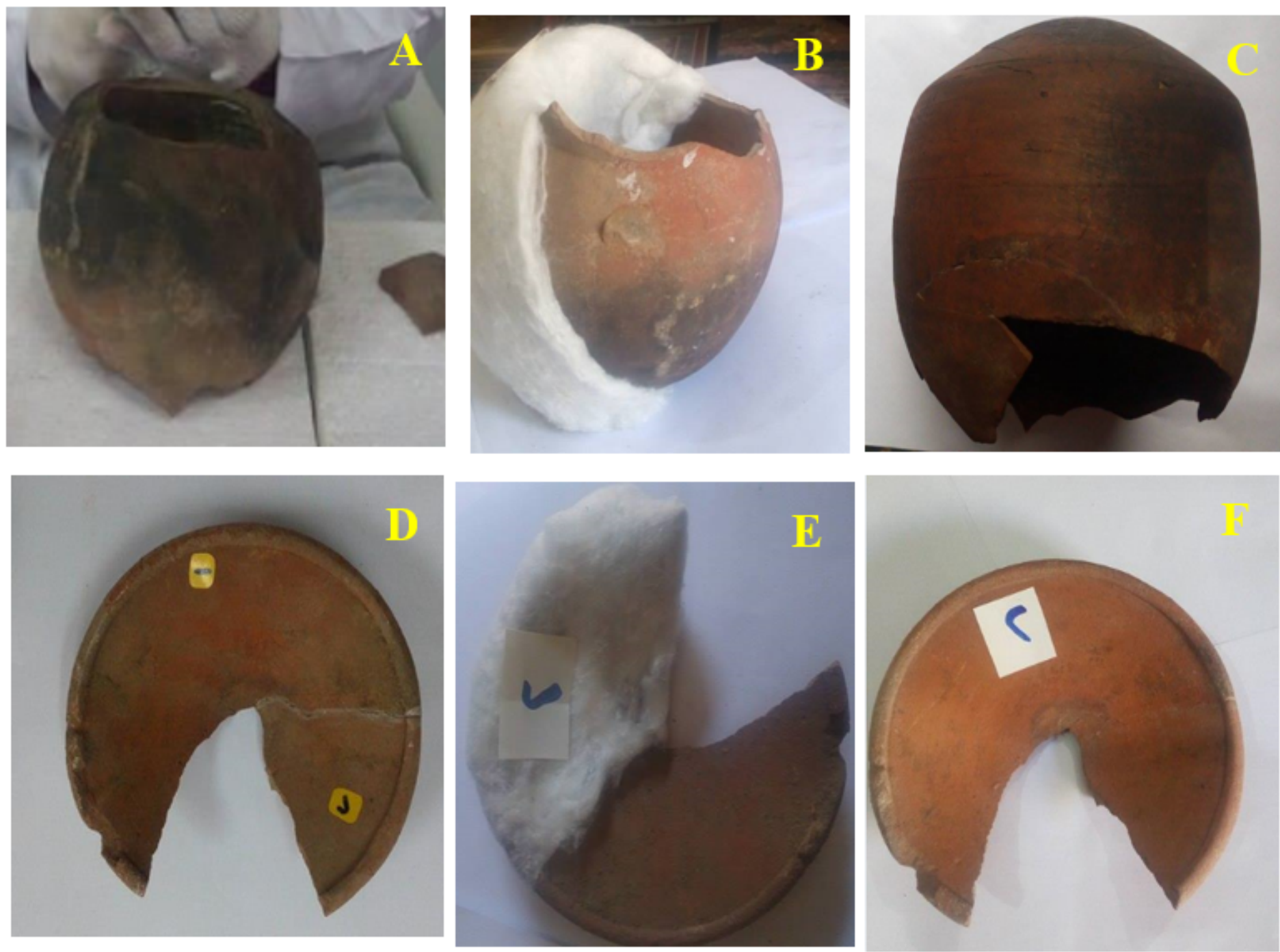

Figure 18

represents cleaning of pottery artifacts a: before cleaning, b: during cleaning, c: after chemical cleaning of the first object, d: the second object before cleaning, e: during cleaning, f: after chemical cleaning 

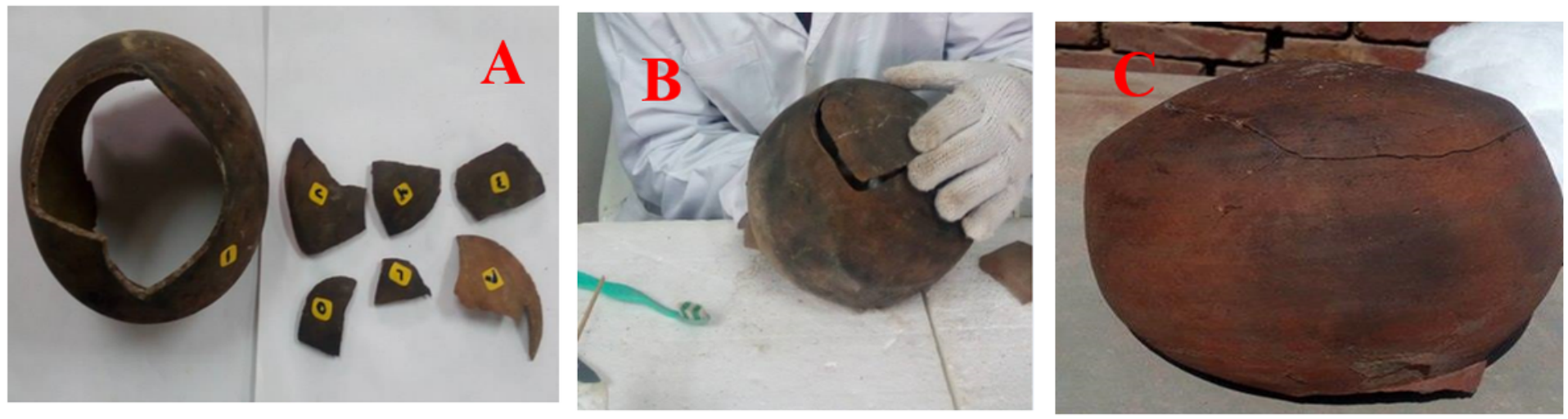

Figure 19

represents the first pottery object, a: before assembly, b: during assembly, c: after assembly
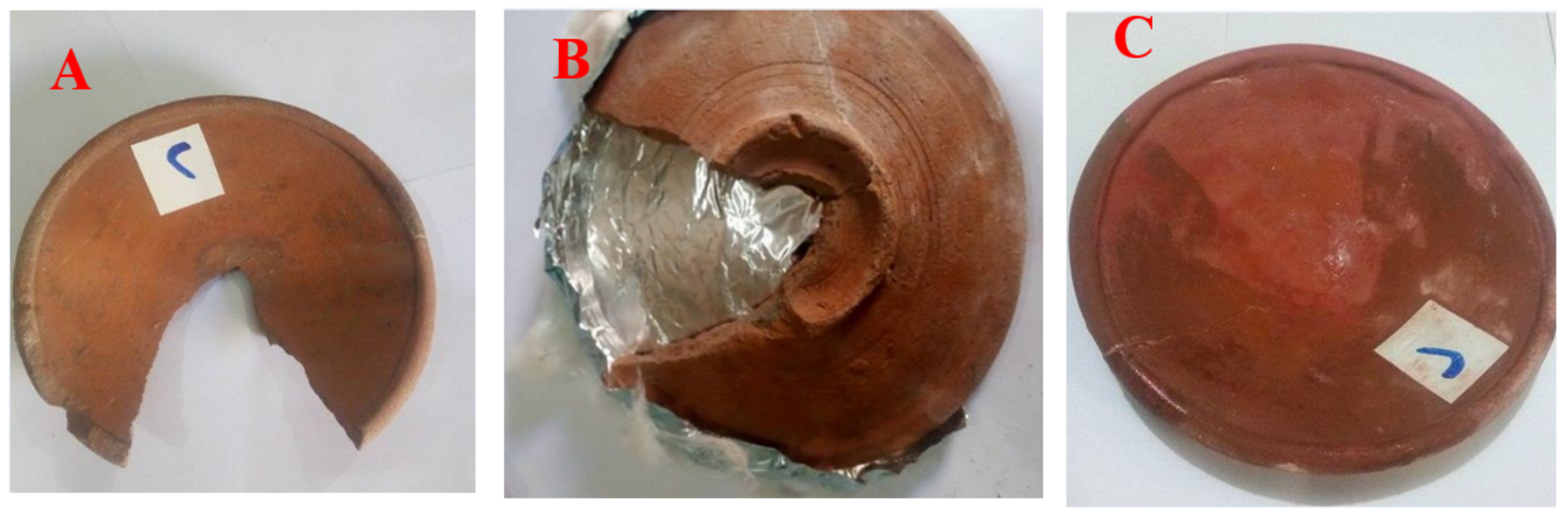

Figure 20

represents the completion of pottery plate, a : Before completion, b: After applying the reinforcing material (aluminum paper), c: After completing the second pottery object 

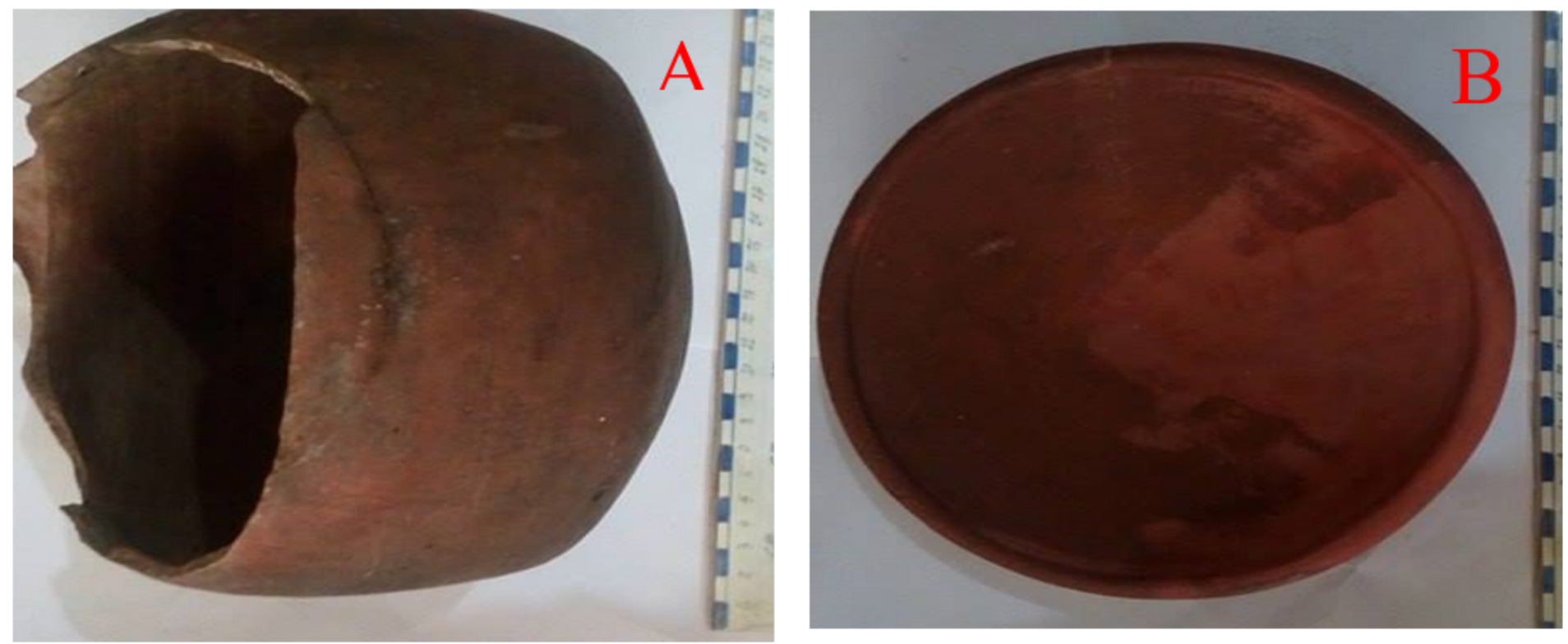

Figure 21

represents the pottery objects after treatment, a: pottery vessel, b: plate 